\section{Obscure overt gastrointestinal bleeding due to Necator americanus diagnosed by double-balloon enteroscopy}

A 63-year-old woman from a rural area of Guatemala was referred to our center because of intermittent melena, weight loss of $5 \mathrm{~kg}$, dyspnea, and malaise of 3 months' duration. In addition, she was experiencing generalized, poorly localized, cramping abdominal pain that was partially relieved with the use of antispasmodics. Her past medical history was significant for hypertension and diabetes mellitus type 2 of 10 years' duration.

On physical examination, her vital signs were stable. She appeared pale, and acanthosis nigricans was observed on her short neck. The cardiovascular examination was significant for a multifocal, holosystolic grade 4 heart murmur. The rectal examination was positive for melena. Laboratory examination revealed the following: hemoglobin, $4.6 \mathrm{~g} / \mathrm{dL}$; hematocrit, $16.3 \%$; mean corpuscular volume, $64.9 \mu \mathrm{m}^{3}$; white cell count, $11150 / \mathrm{mm}^{3}$ with $9 \%$ eosinophils. The remaining laboratory results were within reference ranges. On examination, the stool was guaiac positive but without evidence of parasites.

The results of upper gastrointestinal endoscopy and colonoscopy were unremarkable. Oral (antegrade) double-balloon enteroscopy revealed a large number of worms in the jejunum and ileum ( $\mathrm{Fig} .1$ ). The worms penetrated the mucosa, sucked blood, and moved fast, provoking active mucosal hemorrhage. Uncinariasias due to Necator americanus was diagnosed. A jejunal biopsy revealed an inflammatory infiltrate with eosinophilic predominance. The patient was given a transfusion of packed red blood cells. The parasitosis was successfully eradicated with albendazole (Albenza; GlaxoSmithKline, Philadelphia, Pennsylvania, USA).

This report is unique as for the first time we used double-balloon enteroscopy to document massive parasitosis due to Necator americanus. Uncinariasis should be considered important in the differential diagnosis of obscure overt gastrointestinal bleeding.
Endoscopy_UCTN_Code_CCL_1AC_2AG

Competing interests: None

\section{Bernard A. Reyes-Leiva ${ }^{1}$, Jose L. De León ${ }^{2}$, Fernando Castellanos ${ }^{1,2}$, Edder Sandoval',2, Iván García- Martínez ${ }^{1,2}$}

${ }^{1}$ Department of Gastroenterology, Department of Internal Medicine, Roosevelt Hospital, Guatemala City, Guatemala

${ }^{2}$ Gastrosoluciones, S.A., Guatemala City, Guatemala

\section{Bibliography}

DOI http://dx.doi.org/

10.1055/s-0034-1390723

Endoscopy 2015; 47: E57

(C) Georg Thieme Verlag KG

Stuttgart · New York

ISSN 0013-726X

\section{Corresponding author \\ Bernard Reyes-Leiva, MD}

Department of Gastroenterology,

Department of Internal Medicine

Roosevelt Hospital

Calzada Roosevelt y 5a. Calle, Zona 11

Ciudad de Guatemala 01011

Guatemala

Fax: +502 23217400

drbernard.reyes@gmail.com
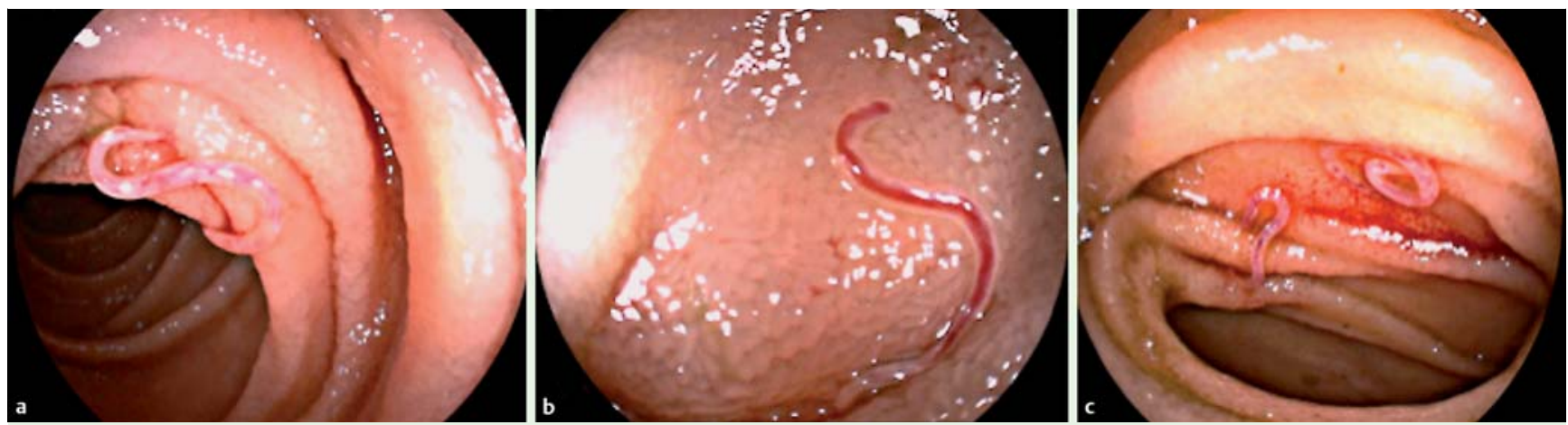

Fig. 1 Necator americanus. a Multiple small, round worms adhere to the small-bowel mucosa. b Some worms are filled with blood. $\mathbf{c}$ The worm infestation is massive. 